\title{
Investigation and Study of the Effect of Sports Health and Dietary Nutrition on Athletes' Physique
}

\author{
Qiang Gao ${ }^{1}$ and Zhen You $^{2}$ \\ ${ }^{1}$ Jining Medical University, Shandong, China \\ ${ }^{2}$ Jining Polytechnic College, Shandong, China
}

Keywords: Dietary nutrition; Competitive sports;Physical condition

\begin{abstract}
Sports health and dietary nutrition is the most important material foundation to ensure the nutrition element needs for athletes and maintain physical fitness, which can plays an important role in guaranteeing the training. However, a common phenomenon is existed, namely, the unbalanced dietary nutrition, which does not suit the important position of the athletes' nutritional dietary in competitive sports. At the same time, it can affect the effect of training and recovery in a long term. In this paper, it chooses 24 athletes as the research object, having investigation on the status of nutrition and health. Then after observing the athletes in the two groups, athletes have made physical diagnosis and physical tests, so as to explore the effects of physical health and dietary nutrition on the physical condition of the athletes.
\end{abstract}

\section{Introduction}

Nutrition and sports are two basic foundations for human health. Human beings must obtain the essential nutrients from food every day to maintain life and health. The daily diet of athletes is one of the important means to restore and improve the body's ability to work. As for food, after the digestion in vivo, it can complete two particularly important functions, namely, replenishing physical energy in time and making compensation during the process of consuming the renewable biological activity substances.

\section{Object and Method}

Randomly selecting twenty four athletes from sports technical college of one certain province, including fifteen male athletes and nine female athletes. At the same time, it can adopt the method of food weighing to make a survey and investigation on the dietary of these twenty four athletes for a week in March, 2015.During the period of investigation, recording athletes daily meal food consumption, weighing and recording each main meal, non-staple food, the weight of raw meal and ripe, so as to calculate the ratio of raw and cooked meal. Moreover, it also should weigh out and record the residual weight of each main and non-staple food that athletes have eaten, so as to calculate out the weight of the food. The amount of water and nutrition of athletes taking should also be recorded, by using software, it can calculate out the amount of the intake of various nutrients and food as well as the composition of food. By comparing the calculated result and the nutrient supplying standard of daily dietary with the food intake and supplying standard, then it can make a reasonable evaluation.

Physical Exercise and Nutrition Education. Athletes in sports health care group had exercises in 
the morning for an hour on every Monday, Tuesday, Thursday, Friday under the guidance of the specialized teachers, while the athletes in ordinary group can not participate in the physical training. After having one year exercise, it can monitor the physical situation of these two groups. Physique monitoring sampling and questionnaire should be made according to the provisions and requirements of the State General Administration of Sports and National Physique Monitoring Center, which also should be in accordance with the requirements of testing methods in Chinese Adult Physique Monitoring Work Manual to monitor physique. During the period of observation, the nutrition education should be provided four times for the athletes in physical health groups regularly.

Data Statistics. The measured data can be statistically analyzed by using SPSS10.0, and the difference between mean and rate can be analyzed by using $t$ test and $\chi^{2}$ test respectively.

\section{Survey on Dietary}

By adopting the weighing method to have a continuous survey on dietary.

(1) Calculating the ratio between the raw food and cooked food, in the kitchen for athletes, taking the weight of rare food of each meal, as well as the weight of food after cooking, so as to calculate the ratio between the raw food and cooked food of a certain kind of food. Thus, the ratio between the raw food and cooked food of a certain kind of food=the weight of a certain kind of cooked food / the weight of a certain kind of raw food .

(2) Calculating the actual consumed weight of the cooked food by survey. In the kitchen for athletes, taking and recording the weight that the investigated objects actually consumed in each meal (cooked weight). The actual consumed weight(cooked weight) of a certain kind of food =the weight of a certain kind of food before meal - the rest weight of food after meal.

(3) Calculating the actual weight of the consumed food, namely, the daily actual consumed wight of raw food of a certain kind of food = the daily weight of the actual consumed weight of the cooked food / the ratio between the raw food and cooked food.

\section{Result}

\section{The Amount of Various Foods that Investigated Objects Intake}

The foods that athletes daily intake are mainly including cereal, milk and fruit, with little amount of some eggs, aquatic products, beans and vegetables, which can be shown in Table 1: 
Table 1 The Amount of Various Foods that Investigated Objects Intake Daily ( $\overline{\mathrm{X}} \pm \mathrm{s})$

\section{Male athletes}

\section{Female athletes}

\begin{tabular}{|c|c|c|c|c|}
\hline Food category & $\begin{array}{c}\text { The amount of } \\
\text { intake (g) }\end{array}$ & $\begin{array}{l}\text { Percentage of } \\
\text { total intake }\end{array}$ & $\begin{array}{c}\text { The amount of } \\
\text { intake (g) }\end{array}$ & $\begin{array}{c}\text { Percentage of } \\
\text { total intake }\end{array}$ \\
\hline Grain cereal & $231 \pm 52$ & 39.0 & $155 \pm 48$ & 35.4 \\
\hline Meat & $66 \pm 30$ & 11.1 & $25 \pm 17$ & 5.7 \\
\hline Aquatic product & $20 \pm 17$ & 3.4 & $15 \pm 12$ & 3.4 \\
\hline Eggs & $13 \pm 8$ & 2.2 & $10 \pm 5$ & 2.3 \\
\hline Milk & $97 \pm 73$ & 16.4 & $78 \pm 44$ & 17.8 \\
\hline Peas and beans & $26 \pm 15$ & 4.4 & $19 \pm 8$ & 4.3 \\
\hline Fruits & $81 \pm 65$ & 13.7 & $80 \pm 44$ & 18.3 \\
\hline Vegetables & $59 \pm 30$ & 9.9 & $56 \pm 22$ & 12.8 \\
\hline Total & 593 & 100.0 & 438 & 100.0 \\
\hline
\end{tabular}

\section{The Amount of Energy and Nutrient that Investigated Objects Intake}

The amount of energy and carbohydrate that male athletes intake was close to the amount of recommendation, while the intake amount of protein and phosphorus was higher the recommended amount. As for the female athletes, the intake amount of energy, protein and fat was lower than the recommended amount, which can be shown in Table 2 . 
Table 2 The Amount of Energy and Nutrient that Investigated Objects Intake Daily ( $\overline{\mathrm{x}} \pm \mathrm{s})$

\begin{tabular}{|c|c|c|c|c|c|c|}
\hline \multirow[b]{2}{*}{$\begin{array}{l}\text { Energy and } \\
\text { Nutrients }\end{array}$} & \multicolumn{3}{|c|}{ Male } & \multicolumn{3}{|c|}{ Female } \\
\hline & $\begin{array}{c}\text { Recommende } \\
\text { d amount } * * \\
*\end{array}$ & Intake amount & $\begin{array}{c}\text { The } \\
\text { value of } \\
\text { R }\end{array}$ & $\begin{array}{l}\text { Recommende } \\
\text { d amount } * * \\
*\end{array}$ & $\begin{array}{l}\text { Intake } \\
\text { amount }\end{array}$ & $\begin{array}{l}\text { The } \\
\text { value } \\
\text { of } \mathrm{R}\end{array}$ \\
\hline $\begin{array}{l}\text { Energy } \\
\text { (kcal) }\end{array}$ & 3500 & $3369.9 \pm 1891.2$ & -0.265 & 2700 & $\begin{array}{c}1355.8 \pm 367 \\
5\end{array}$ & -10.96 \\
\hline Protein (g) & 118 & $177.8 \pm 91.6^{*}$ & $\begin{array}{c}2.52567 \\
4\end{array}$ & 91 & $67.2 \pm 16.0^{*}$ & $\begin{array}{c}-4.434 \\
7\end{array}$ \\
\hline Fat (g) & 107 & $8 . \pm 41.2$ & -1.95055 & 75 & $46.4 \pm 11.2^{*}$ & $\begin{array}{c}-7.660 \\
6\end{array}$ \\
\hline $\begin{array}{c}\text { Carbohydrat } \\
\text { e (g) }\end{array}$ & 481 & $\begin{array}{c}481465.2 \pm 231 \\
1\end{array}$ & -0.26467 & 370 & $364.3 \pm 61.1$ & $\begin{array}{c}-0.279 \\
3\end{array}$ \\
\hline
\end{tabular}

\section{The Functional Ratio of Three Major Production Capacity Nutrients that Investigated Objects Intake}

Among the percentage of three major nutrients intake of the athletes, the intake of protein is high, fat is low, while carbohydrates are basically in the range of the recommended standard. At the same time, the percentage of three major nutrients intake of the male and female athletes is very close to each other, which can be shown in Table 3 .

Table 3 The Functional Ratio of Three Major Production Capacity Nutrients that Investigated Objects Intake $(\overline{\mathrm{x}} \pm \mathrm{s})$

\begin{tabular}{cccc}
\hline Nutrients & $\begin{array}{c}\text { Recommended } \\
\text { functional ratio }\end{array}$ & Male athletes & Female athlete \\
\hline Protein & $12-15$ & 25 & 24 \\
& & & \\
Fat & $25-30$ & 16 & 15 \\
Carbohydrate & $50-60$ & 59 & 61 \\
Total & & 100 & 100 \\
\hline
\end{tabular}




\section{Physical Test Results}

The related laboratory examination data of athletes' physique, after having regular quantitative physical exercises, the amount of hemoglobin, albumin in health care group was significantly higher than that in the normal group, while the amount of glucose, triglyceride and cholesterol was significantly lower than that in the normal group. Compared with the normal group before and after the experiment, the amount of hemoglobin, albumin was decreased, while the amount of triglyceride and cholesterol was rising. As for the health care group, compared with these data before and after the experiment, the amount of hemoglobin and albumin was increased, while the amount of glucose, glycerol fat and cholesterol was decreased.

\section{The Intake Amount of All Kinds of Food Is Unbalanced}

In the dietary constitution, the amount of cereals among male and female athletes can be accounted for $39.0 \%$ and $35.4 \%$ of the total intake amount, while animal food can be accounted for $33.1 \%$ and $29.2 \%$ respectively, fruits and vegetables can be accounted for $23.6 \%$ and 31.1\%respectively. Moreover, the dietary constitution between meat and vegetable should be reasonable, but compared with the reference intake amount of Chinese Dietary Guideline and Balance Diet Pagoda, the amount of intake food was significantly lower, especially fruits and vegetables, which only can be accounted for $23.3 \%$ and $22.7 \%$ of the reference value.

\section{Intake Energy and Three Major Nutrients}

Generally speaking, it is normal that the intake of energy should be accounted for 90 percentage of the recommended intake amount, if it is below 80, it can be regarded as the lack of intake. This survey has shown that the energy intake of male athletes can be within normal range, but the energy intake of female athletes is only accounted for $50.2 \%$ of the recommended value. Such a low energy intake can not meet the needs of female athletes' training. As for the respect of three major nutrients intake, protein intake amount of male athletes is higher than that of the normal value, while female athletes is lower than that of the normal value.Besides, it is basically normal that male athletes can intake enough fat, while female athletes intake much fewer, but the amount that both of them intake carbohydrate is in the normal range. From the above, we can see that the heat of female athletes is mostly in a negative balance, who should strengthen the intake of protein, fat, eggs, meat, milk, beans as well as its side product, so as to increase food supplies, but for male athletes, who may be appropriately reduce these foods such as eggs, milk and so on, which can contain high protein food.

\section{Conclusion}

Because athletes belong to a special group, who should ensure their bodies be in the physiological and biochemical functions and remain them in the best condition. Therefore, on one hand the athletes should control dietary intake level, at the same time, they should pay attention to a reasonable balanced diet. Athletes' food should meet the consumption of sports training or competition in amount, which also should maintain the appropriate weight and body fat. Only in this way can it ensure the comprehensive nutritional needs and appropriate proportion in quality. 


\section{References}

[1]De Vito G, Di Filippo L, Rodio A, Felici F, Madaffari A. 1997. Is the Olympic boardsailor an endurance athlete? Sports Med. vol.18, pp281-284.

[2]I. Vogiatzis, G. De Vito, A. Rodio, A. Madaffari, M. Marchetti. 2002. The physiological demands of sail pumping in Olympic level Windsurfers. Appl Physiol. vol.86, pp450-454.

[3] Guezennc et cl. 1998. Is there a relationship between physical activity and dietary calcium intake.A survey in 10, 373 young French subjects. Med Sci Sport Exxerc. vol.305, pp732-739.

[4] Nowak RK et cl. 1988. Body composition and nutrient intakes of college men and women basketball players, J Am Diet Assoc. vol.88, pp575-578.

[5]Schrodel H, Nararro E, Tramullas A, et al. 2000. Nutrition Antioxidant status and Oxidative stress in Professional basketball players. Sport Med, vol.21, pp146. 